\title{
A situação atual do mercado da saúde suplementar no Brasil e apontamentos para o futuro
}

\author{
The current situation of the private health plans \\ and insurance market in Brazil and trends for the future
}

Ceres Albuquerque ${ }^{1}$

Márcia Franke Piovesan ${ }^{1}$

I sabela Soares Santos ${ }^{1}$

Ana Cristina M arques M artins ${ }^{1}$

Artur Lourenço Fonseca ${ }^{1}$

Daniel Sasson ${ }^{1}$

Kelly de Almeida Simões ${ }^{1}$

\footnotetext{
${ }^{1}$ Agência N acional de Saúde Suplementar. Av. Augusto Severo $84 / 10^{\circ}$ andar, Glória. 20021-040 Rio deJaneiro RJ.ceres@ans.gov.br
}

Abstract This paper presents an overview of the Brazilian private health plan market over the period 2000-2006. The current situation is analyzed with respect to the profile of private insurance companies, health plansand beneficiariesand some possible trends that were identified in the study are emphasized. The increase of employer groupplans as a work-related benefit and the reduction of individual plans are discussed. Although the market is restricted to only a few companies, there are more people covered by local plans than by plans offering coverage on a national basis. Finally, the paper approaches aspects related to the financial resources, among them the governmental incentive for the health area, and points to the need of further studies for a better understanding of the supplementary healthcare market.

Key words Private health plans, Supplementary $\mathrm{H}$ ealth, O perators of supplementary health plans, $\mathrm{N}$ acional Agency of Supplementary $\mathrm{H}$ ealth
Resumo 0 artigo tem por objetivo descrever a situação do mercado de planos privados de assistência médica no Brasil, no período de2000 a 2006. Analisa a situação atual no quetangeaos beneficiários, às operadoras eaos planos de saúdee destaca algumas possíveis tendências sinalizadas pelo estudo. A presenta o perfil dos beneficiários e a cobertura por planos na população.Discutea expansão dos planos col eti vos, a redução dos planosindividuais, bem como a acentuada concentração de beneficiários em poucas operadoras, identificando que, apesar de tratar-se de um mercado concentrado, há mais beneficiários em planoscom abrangência municipal ou regional do que em planos nacionais. Por fim, aborda aspectos relacionados aos recursos financeiros, entre eles 0 incentivo governamental para o setor e conclui sinalizando a necessidade de estudos para melhor conhecer a dinâmica do mercado de planos privados de saúde. Palavras-chave Planos privados de saúde, Saúde suplementar, O peradoras de planos privados de saúde, A gência N acional de Saúde Suplementar 
Introdução

0 mercado dos planos privados de assistência à saúde está relacionado, desde o seu início, à urbanização, à industrialização do país, à renda e ao emprego formal. Por tratar-se de um segmento não normatizado até 1998, e não regulado no âmbito da saúde até a Lei no 9.656/98, as operadoras de planos privados atuavam no atendimento aos beneficiários a partir de critérios próprios do mercado.

Pouco se conhece sobre o crescimento do mercado de saúde suplementar, em âmbito nacional, até $o$ ano 2000, devido à ausência ou fragmentação das fontes de informação anteriores a este ano. H oje, o mercado de saúde suplementar é composto pelos planos privados (oferecidos por pessoas jurídicas de direito privado) e por planos vinculados à instituição patronal de assistência ao servidor público civil e militar, estes últimos não regulados pela Agência $\mathrm{N}$ acional de Saúde Suplementar (ANS). Segundo dados da Pesquisa Nacional por Amostra de Domicílios, PNAD/IBGE de 20032, os dois segmentos detinham, respectivamente, $79,2 \%$ e $20,8 \%$ dos beneficiários de planos de saúde no Brasil.

Os planos privados de assistência à saúde possuem duas grandes segmentações: planos de assistência médica (que podem incluir assistência hospitalar, ambulatorial e odontológica) e planos exclusivamente odontológicos. Este artigo tem por objetivo analisar a situação atual do mercado de planos privados de assistência mé dica. Os planos exclusivamente odontológicos não são objeto de análise nesse trabalho. Em sua primeira parte, a exposição aborda fatos referentes à regulamentação do setor e à criação da ANS. Na segunda, são analisados aspectos da situação atual do mercado no que tange aos beneficiários, às operadoras e aos planos de saúde e algumas interfaces do mercado com o sistema público de saúde e, por fim, abordam-se algumas possíveis tendências sinalizadas na análise.

\section{Material emétodos}

Para o estudo, foram utilizados dados públicos oriundos dos sistemas de informações de beneficiários, de planos e os relacionados às operadoras, todos sob a gestão da ANS. A análise foi complementada com informações do Instituto Brasileiro de Geografia e Estatística (IBGE), microdados da Pesquisa Nacional por Amostra de Domicílios (PNAD) de 2003 e da Pesquisa de
Orçamentos Familiares (POF) de 2003, bem como dados da Pesquisa de Assistência M édicoSanitária (AM S) de 2005.

Os termos relacionados aos beneficiários, operadoras e planos são os definidos pelas normas que regulam o mercado de planos privados de saúde. São destacadas a seguir algumas definições importantes utilizadas neste artigo. Por beneficiários, compreende-se os vínculos a planos desaúde. Um mesmo indivíduo podeter mais de um plano e, assim, mais de um vínculo contratual. O Sistema de Informações de Beneficiários (SIB) registra vínculos aos planos, sendo, portanto, o número de vínculos de beneficiários um pouco maior que o número de indivíduos. Usando como parâmetro a PNAD/IBGE, em 2003, as pessoas com mais de um plano representavam $4 \%$ do total de beneficiários. Devido a essa limitação, os cálculos de cobertura são uma aproximação.

Os planos privados de saúde podem ser contratados individual ou coletivamente. 0 contrato individual éassinado entreum indivíduo euma operadora para a assistência do titular do plano e de seus dependentes, enquanto que o contrato coletivo éo assinado entreuma pessoa jurídica e a operadora para a assistência dos empregados, funcionários e dependentes, sejam ativos ou inativos, ou de sindicalizados e associados da pessoa jurídica contratante. Os contratos coletivos podem ser empresariais ou por adesão; nos primeiros, o ingresso éautomático no ato da vinculação do usuário à pessoa jurídica contratante, no segundo tipo, a adesão é opcional.

Quanto à época de contratação, os planos podem ser posteriores à Lei $n$ o 9.656/98, chamados de planos novos, e podem ser antigos, ou seja, anterioresàregulamentação ecom diferençasquanto ao escopo da regulação realizada pela ANS.

As operadoras estão organizadas em modalidades, segundo seu estatuto jurídico:

. Autogestão: entidades de atividades econômicas outras que não a saúde, que operam serviços de assistência à saúde, em rede própria ou de terceiros, destinados, exclusivamente, a seus empregados e dependentes;

- Cooperativa médica: sociedades sem fins lucrativos, caracterizadas por cooperativismo de profissionais médicos, conforme 0 disposto na Lei no 5.764/71, queestabelecea Política Nacional de Cooperativismo;

. Filantropia: entidades sem finslucrativosque operam planos privados, certificadas como entidadefilantrópica junto ao Conselho $\mathrm{N}$ acional de Assistência Social; 
- Seguradora especializada em saúde: socie dades seguradoras autorizadas a operar planos de saúde;

- M edicina de grupo: demais empresas ou entidades que operam planos privados de assistência à saúde.

As mudanças trazidas

com a regulamentação

dos planos privados de saúde

A trajetória da organização do sistema de saúde no país e do mercado de planos privados de assistência à saúde tem sido objeto de estudos de vários autores, a exemplo, Cordeiro ${ }^{3}$, Oliveira et al. ${ }^{4}$, N oronha ${ }^{5}$, Faveret ${ }^{6}$, Almeida ${ }^{7,8}$, Bahia $a^{9,10}$, Oliveira et al. ${ }^{11}$, Lima et al..$^{12}$. Não sendo o intuito deste artigo reconstituir a história deste mercado, no que segue destacamos os principais fatos e as principais mudanças relacionadas à sua regulamentação.

O desenvolvimento da indústria no Brasil, principalmente a automobilística, a partir da dé cada de 1950 e o deslocamento da economia do setor agrário para os centros urbanos influenciaram a organização da assistência à saúde no país. Empresários estrangeiros organizaram junto aos prestadores de serviço uma assistência médica e hospitalar específica para seus empregados ${ }^{13}$.

A industrialização crescente levou à criação de empresas e esquemas próprios de assistência médico-hospitalar, também motivada pelo empresariamento e pela capitalização da medicina, que ocorreu por meio de financiamentos governamentais que fortaleceram o setor privado na prestação de serviços de saúde $e^{4}$. Profissionais de saúde e prestadores de serviços identificaram a possibilidade de oferecer acesso a serviços de saúde a uma importante parcela da população das regiões urbanas e industrializadas, que possuía vínculo formal de trabalho nas indústrias de transformação, metalurgia e química.

Estes fatores estimularam o credenciamento de serviços, contribuindo para a expansão do mercado, particularmente de empresas de medicina de grupo e cooperativas médicas ${ }^{13}$.

Até a década de 1980, os planos de saúde estavam voltados para trabalhadores inseridos no mercado formal. A partir da segunda metade dos anos 1980, as operadoras de planos de saúde expandiram seus negócios para clientes individuais ${ }^{9}$.

A Constituição Federal de 1988, que estabelece 0 direito social à saúde, a universalização da assistência ea conformação de um sistemaúnico de saúde, regulamentado pela Lei Orgânica da Saúde (no 8.080/90), não faz referência específica ao setor de saúde suplementar.

A promulgação da Lei do Código de Defesa do Consumidor ( $n=8.078 / 90)^{14}$ exerceu forte influência nos acontecimentos no decorrer da década de 1990 no mercado de planos privados.

Nos primeiros anos da década de 1990, o debate sobre os planos de saúde possuía como pontos principais: elaboração de regras de solvência para as operadoras de planos de saúde, abertura do setor para o capital estrangeiro, reivindicações de ampliação de cobertura econtroledepreços defendidos pelas entidades médicas e de defesa do consumidor.

A demanda por regulamentação governamental foi constituída por muitos temas, representados por diferentes atores e interesses ${ }^{15}$, que resultaram em acordo entre os Poderes Executivo e Legislativo para a aprovação da Lei no 9.656, de junho de 1998, quedispõe sobreos planos eseguros privados de assistência à saúde. Até a regulamentação, as empresas de planos privados de saúde estavam sujeitas a um controlegovernamental irrisório, à exceção das seguradoras, normatizadas pelo M inistério da Fazenda (SUSEP/M F), no quetange aos aspectos econômico-financeiros. A criação do Departamento de Saúde Suplementar (DESAS), no M inistério da Saúde, em 1998, foi um primeiro passo para a regulação do mercado de planos privados de saúde.

Em 2000, foi criada a Agência $\mathrm{N}$ acional de Saúde Suplementar (ANS), no âmbito do M inistério da Saúde, com a finalidadeinstitucional de promover a defesa do interesse público na assistência suplementar. Sua área de ação compreendia um mercado já em funcionamento, que se expandiu desordenadamente, constituído por diversostipos deplanosedeoperadoras queatendiam a uma grande variedade de interesses e nichos de mercado.

0 marco regulatório da assistência suplementar privada é composto pela a Lei no 9.656, de 1998, e pela Lei no $9.961^{16}$, de 2000, na qual estão definidas as competências da ANS. A regulamentação trouxe mudanças importantes, a maioria restrita aos planos registrados a partir de janeiro de 1999 (conhecidos como planos novos), não garantindo os mesmos direitos aos beneficiários de planos anteriores a essa data (planos antigos).

Entre as mudanças introduzidas se destacam: obrigação de oferta de ampla cobertura dos serviços de saúde, incluindo assistência a todas as patologias da Classificação Internacional deDoenças (CID-10), a assistência psiquiátrica eos trans- 
plantes derim edecórnea, ea proibição do limite do tempo e do número de internações e procedimentos. Também foram definidas regras para os casos de beneficiários demitidos do emprego, aposentados e portadores de doença ou lesão anterior à aquisição do plano; tempo máximo decarência, atendimento deurgência eemergência (para planos novos e antigos); e rescisão de contrato por parte da operadora e parâmetros para a sustentabilidade econômica das operadoras (reservas técnicas e provisões financeiras).

No que tange ao reajuste de mensalidades, a regulamentação trata de modo diferente os planos individuais e os coletivos: o primeiro caso tem seu índice definido pela ANS, ao passo que nos planos coletivos existe uma livre negociação entre as partes, posteriormente informada à ANS. Esta diferença na legislação presume o poder de negociação que empresas, associações e sindicatos (pessoas jurídicas) teriam na contratação de planos, em função do número de beneficiários vinculados; todavia, uma parcela destes contratantes possui poucos beneficiários, acarretando um baixo poder de negociação.

Um resultado importante da regulação foi 0 conhecimento do perfil deste mercado e de sua abrangência no sistema de saúde brasileiro, insumos indispensáveis para o planejamento e formulação de políticas públicas. A partir da criação da ANS, as operadoras foram obrigadas a informar periodicamente dados econômico-financeiros; características dos planos comercializados: serviços cobertos, rede prestadora, tipo de contratação, abrangência geográfica, segmentação assistencial e utilização de serviços, bem como dados dos ben eficiários que possibilitam conhe cer o perfil de idade, sexo elocal de residência.

A téo início da regulação governamental, pouco se conhecia sobre o mercado de planos privados de saúde no país pois, além das informações oriundas de pesquisas como a Pesquisa Nacional por Amostra Domiciliar e a Pesquisa de Orçamentos Familiares do IBGE, as demais informações existentes eram as geradas pelos próprios integrantes do mercado. Dessa forma, a finalidade da AN S de promover a defesa do interesse público na assistência suplementar e, entreas suas competências, a de reunir informações básicas sobre operadoras, beneficiários e planos de saúde, é realizada nesse contexto, que éo de um setor que até então não fornecia os dados periódicos para o Estado, o que dificulta imensamenteo trabal ho de coleta, análise e divulgação de informações sobre o setor.

Entretanto, mesmo depois de iniciada a re gulação do setor, foi grande a resistência das operadoras em enviar dados sobre seus beneficiários, seus planos e suas receitas e despesas. Um avanço importante ocorreu após outubro de 2003, quando o Supremo Tribunal Federal (STF) julgou recurso sobre a Ação Direta de Inconstitucionalidade, ADIN № 1931, movida pela Confederação Nacional de Saúde, H ospitais, Estabelecimentos eServiços, que solicitou liminar para suspender a Lei no 9.656/98 por considerá-la inconstitucional. O STF deferiu a liminar apenas para um Artigo da Lei (o 35-G), mantendo ereconhecendo a constitucionalidade de todos os demais artigos que regulamentavam os planos privados de saúde.

A partir do ano de 2003, verifica-se o aumento da regularidade do envio de dados, bem como 0 aperfeiçoamento da sua qualidade, demonstrada pela redução do número de beneficiários de planos antigos com tipo de contratação não identificada e pela análise das bases de informação constantes nos resultados do Programa de Qualificação da Saúde Suplementar. Este programa permite, a partir de seus resultados, fazer um diagnóstico da qualidade das operadoras e, conseqüentemente, das informações por elas enviadas.Visa incentivar a melhoria da qualidade da assistência à saúde prestada aos beneficiários de planos privados e da própria estrutura e condições econômico-financeiras das operadoras, por meio de indicadores de saúde, da satisfação dos beneficiários, das condições econômico-financeiras e de estrutura para operação das operadoras.

\section{Situação atual : beneficiários, operadoras e planos privados desaúde}

O mercado de planos privados é expressivo no sistema de saúdebrasileiro. Em dezembro de2006, envolvia 44,7 milhões de vínculos de beneficiári0S, dos quais $82,7 \%$ a planos de assistência médica e $17,3 \%$ a planos exclusivamente odontológicos, 2.070 empresas operadoras, mais devinte mil planos e milhares de prestadores de serviços ${ }^{17}$.

Do total de vínculos a planos privados, cerca de 36,9 milhões são de assistência médica, o que significa uma cobertura aproximada de 19,8\% da população brasileira, distribuída de maneira desigual entre as regiões do país. É maior entre os residentes nas áreas urbanas e nos estados com maior renda emaior oferta de emprego formal e de serviços de saúde, situação encontrada nas regiões sudeste e sul do país, nas quais a maioria das capitais apresenta taxas de cobertu- 
ra superiores a 40\%, a exemplo de Vitória $(67,6 \%)$, São Paulo $(59,2 \%)$, Rio de Janeiro (49,0\%) e Florianópolis (44,9\%).

Nos últimos anos, o crescimento proporcional dos vínculos de ben eficiários com assistência médica acompanhou o da população brasileira: em dezembro de 2000, representava uma cobertura aproximada de $18,7 \%$ e, em dezembro de 2006, 19,8\%. Na maior parte dos municípios do país (70\% dos 5.564 municípios), a cobertura é menor que $5 \%$ da população. A concentração maior de beneficiários encontra-se em $30 \%$ dos municípios do país, onde reside $70 \%$ da população brasileira (Figura 1).

A cobertura de beneficiários idosos (60 ou mais anos) passou de $22,7 \%$, em dezembro de 2000, para 25,6\%, em dezembro de 2006 (Figura 2). 0 número de beneficiários idosos aumentou de 3,2 milhões para 4,0 milhões. A cobertura de beneficiários na faixa etária de 0 a 19 anos passou de $14,8 \%$, em dezembro de 2000 , para $13,8 \%$, em dezembro de 2006 e na faixa etária de 20 a 59 anos, passou de $21,0 \%$ em 2000 para $23,5 \%$, em 2006. 0 aumento absoluto nesse período foi de aproximadamente 297 mil beneficiários na faixa etária de 0 até 19 anos e 4,3 milhões na faixa etária de 20 a 59 anos. Em relação ao percentual

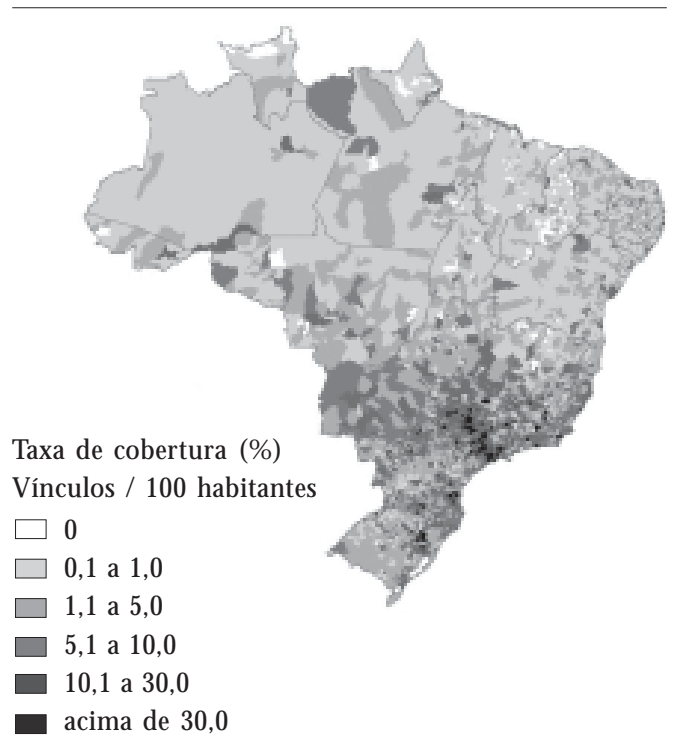

Figura 1. Taxa de cobertura dos beneficiários de planos de assistência médica, por município. Brasil, 2006.

Fontes: Sistema de Informações de Beneficiários - AN S/M S12/2006 e População estimada - IBGE eD atasus - 2006. de beneficiários por faixa etária, em 2000, 31,8\% dos beneficiários tinham até 19 anos, 57,6\%, de 20 a 59 anose $10,4 \%, 60$ anos ou mais, eem 2006 esses percentuais são, respectivamente, $28,0 \%$, $60,9 \%$ e $10,9 \%$.

A cobertura por planos de saúde, seja público ou privado, está associada à renda da população. Entre os 10\% com menor renda na população brasileira (primeiro décimo), 1,3\% tem planos privados e 1,0\%, planos públicos. 0 percentual da população com plano em cada décimo de renda cresce progressivamente, até que entre os $10 \%$ de maior renda, verifica-se que $31,1 \%$ têm planos privados e 28,6\% têm planos públicos (Figura 3). A mesma relação entre renda e cobertura da população com plano pode ser observada quando seassocia a população coberta ao statusocupacional e ao número de anos de estudo ${ }^{18}$.

Outra característica do perfil de beneficiários é a cobertura maior entre os que têm emprego formal, situação na qual a posse do plano se dá por meio de seus empregadores. Em dezembro de2006, 70\% dos beneficiários de planos deassistência médica estavam em planos coletivos e $22 \%$, em planos individuais, como mostra a Tabela 1. A análise da evolução do número de beneficiáriOS, segundo o tipo de contratação do plano, apresenta contínuo aperfeiçoamento, demonstrado pelo fato de que, no ano 2000, as operadoras não informavam o tipo de contratação dos planos de $49 \%$ do total de beneficiários, ao passo que no ano de 2006 este problema é da ordem de 8\%.

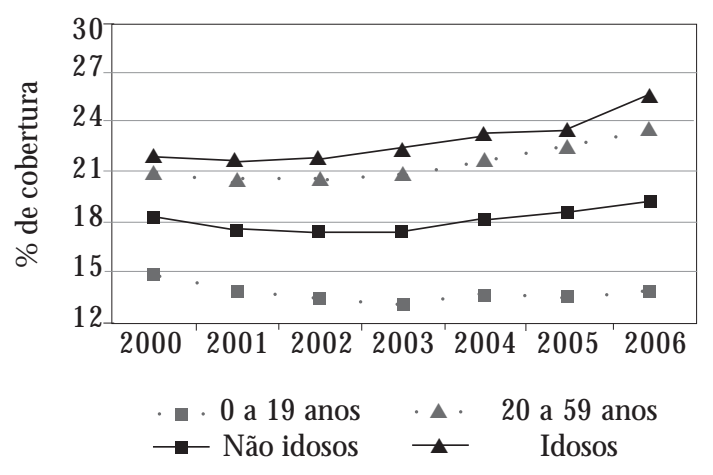

Figura 2. Taxa de cobertura dos beneficiários de planos de assistência médica, por grupos etários. Brasil, 20002006.

Fontes: Sistema de Informações de Beneficiários - ANS/M S - 12/ 2006 e População estimada - IBGE e Datasus - 2006. 


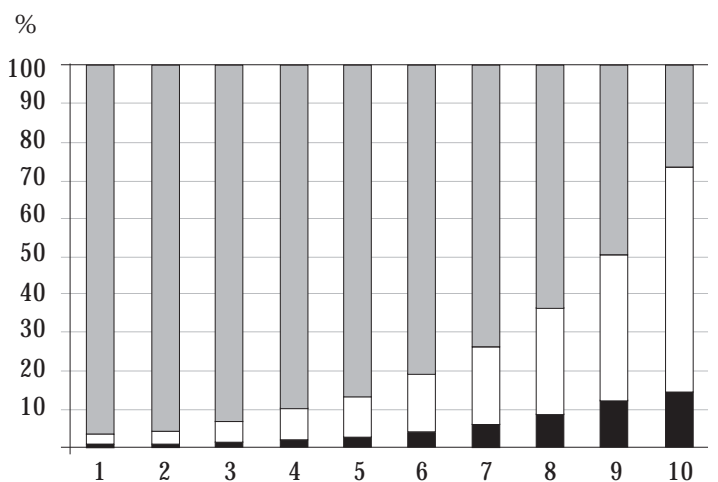

População ordenada pelo decil de renda familiar per capita

não tem plano

plano privado

plano público

Figura 3. Distribuição percentual da população brasileira segundo a posse de plano de saúde e a renda familiar per capita. Brasil, 2003.

Fonte: Elaboração própria a partir dosmicrodados PNAD/ IBGE- 2003.

Nesse sentido, para aferir se houve aumento real dos planos coletivos ou se os beneficiários eram de planos coletivos e não estavam sendo identificados, foi feita a análise do aumento do número absoluto de beneficiários destes planos. Constatou-se que o número de beneficiários em planos coletivos aumentou mais do que o correspondente aos beneficiários em planos com tipo de contratação não identificada, o que demonstra seu incremento real entre 2000 e 2006 (Tabela 1). Quando se investigou em quais modalidades este incremente ocorreu, verificou-se que se deu principalmente nas cooperativas médicas. $\mathrm{Nas}$ seguradoras de saúde, o aumento de beneficiários em planos coletivos foi associado à sua redução nos planos individuais.

No início do ano 2000, estavam registradas 1.968 operadoras médico-hospitalares. Vale observar, entretanto, que o maior movimento ocorreu nos primeiros anos da regulamentação, épo$\mathrm{ca}$ em que as novas normas ainda não estavam completamentecompreendidas, tendo sido registradas como operadoras algumas empresas de prestação de serviços médicos, empresas que financiavam planos de saúde para seus empregados, empresas que pretendiam criar planos de saúde e mesmo algumas empresas que nada ti- nham a ver com a saúde suplementar. Hoje, ainda podem ser encontradas no cadastro da ANS 236 operadoras sem beneficiários.

Ao longo deste período, até 2006, 329 novas operadoras foram registradas e 810 canceladas. 0 maior número de cancelamentos em relação aos novos registros pode estar associado ao processo de regulação e regulamentação, que impôs exigências econômico-financeiras e de prestação de serviços para as operadoras, ou seja, ao estabelecimento de padrões aceitáveis para operação no setor.

Quando se observa a quantidade de beneficiários das 1.239 operadoras que comercializam planos de assistência médica, verifica-se uma grande concentração em poucas operadoras: $20 \%$ dos beneficiários nas sete maiores operadoras; metade dos beneficiários em 44 operadoras e 854 operadoras com apenas $10 \%$ do total de beneficiários, 0 que mostra uma grande concentração do mercado de planos de assistência médica (Figura 4).

Com relação à abrangência dos planos de assistência médica, 47,2\% dos beneficiários possuem cobertura para planos municipais ou grupo de municípios, $14,4 \%$, estaduais ou grupo de estados e $30 \%$, planos nacionais. Não foi identificada a abrangência dos planos de 8,5\% dos beneficiários. Como mostra a Tabela 2, entre as 1.239 operadoras que oferecem planos de assistência médica, 836 comercializam pelo menos um plano de grupo de municípios. Essas informações sugerem que, embora muitos dos beneficiários estejam concentrados em poucas e grandes operadoras, também é muito significativa a pulverização do mercado em operadoras que comercializam planos regionais.

Segundo dados da pesquisa AMS/IBGE, em 2005, a mai oria dos estabelecimentos com internação (62\%), dos leitos (66\%) e das unidades com serviço de apoio à diagnose e terapia (92\%) do país é privada, enquanto a maioria das unidades ambulatoriais ( $75 \%$ ) é pública.

Em que pese a natureza privada do prestador da assistência hospitalar, a provisão dos serviços é predominantementepública. Para a prestação dos serviços públicos, o Sistemaú nico de Saúdeutiliza hospitais próprios ehospitais privados, sendo que $69 \%$ dos hospitais privados e $65 \%$ dos leitos privados estão contratados ou conveniados ao SUS. 0 restante dos leitos (35\%) está disponível para a assistência suplementar ou para serviços financiados pelo desembolso privado direto. Parte dos leitos em hospitais públicos não está disponível para o SUS, pois pertencem a hospitais militarese instituições de previdência estadual emunicipal. 
Tabela 1. Beneficiários de planos de assistência médica, por tipo de contratação, segundo a modalidade da operadora. Brasil, 2000-2006.

\begin{tabular}{|c|c|c|c|c|}
\hline & Total & Coletivo & Individual & Não identificado \\
\hline \multicolumn{5}{|l|}{ Total } \\
\hline 2000 & 31.679 .250 & 10.862 .796 & 5.219 .346 & 15.597 .108 \\
\hline 2001 & 31.092 .826 & 12.904 .068 & 6.086 .739 & 12.102 .019 \\
\hline 2002 & 31.190 .166 & 15.420 .614 & 6.656 .059 & 9.113 .493 \\
\hline 2003 & 31.705 .042 & 18.778 .583 & 7.296 .917 & 5.629 .542 \\
\hline 2004 & 33.423 .763 & 21.729 .191 & 7.821 .919 & 3.872 .653 \\
\hline 2005 & 35.151 .348 & 23.814.339 & 8.169 .453 & 3.167 .556 \\
\hline 2006 & 36.953 .198 & 25.736 .206 & 8.348 .234 & 2.868 .758 \\
\hline \multicolumn{5}{|c|}{ Autogestão } \\
\hline 2000 & 5.233 .807 & 3.125 .898 & 78.779 & 2.029 .130 \\
\hline 2001 & 5.179 .476 & 3.175 .308 & 82.811 & 1.921 .357 \\
\hline 2002 & 5.194 .085 & 3.374 .665 & 89.417 & 1.730 .003 \\
\hline 2003 & 5.208 .036 & 3.757 .731 & 93.128 & 1.357 .177 \\
\hline 2004 & 5.359 .795 & 4.129 .833 & 96.061 & 1.133 .901 \\
\hline 2005 & 5.312 .008 & 4.108 .061 & 97.269 & 1.106 .678 \\
\hline 2006 & 5.399 .644 & 4.197 .862 & 100.264 & 1.101 .518 \\
\hline \multicolumn{5}{|c|}{ Cooperativa médica } \\
\hline 2000 & 7.838 .285 & 2.566 .599 & 1.653 .012 & 3.618 .674 \\
\hline 2001 & 8.236 .471 & 3.318 .590 & 1.963 .667 & 2.954 .214 \\
\hline 2002 & 8.403 .442 & 4.143 .485 & 2.221 .403 & 2.038 .554 \\
\hline 2003 & 9.076 .582 & 5.154 .325 & 2.566 .651 & 1.355 .606 \\
\hline 2004 & 9.911 .442 & 6.122 .055 & 2.821 .558 & 967.829 \\
\hline 2005 & 10.953 .086 & 7.084 .830 & 3.091 .953 & 776.303 \\
\hline 2006 & 11.942 .628 & 8.025 .601 & 3.258 .272 & 658.755 \\
\hline \multicolumn{5}{|c|}{ Filantropia } \\
\hline 2000 & 1.133 .058 & 274.503 & 341.174 & 517.381 \\
\hline 2001 & 1.131 .802 & 342.211 & 361.365 & 428.226 \\
\hline 2002 & 1.108 .052 & 394.724 & 383.023 & 330.305 \\
\hline 2003 & 1.060 .943 & 457.278 & 403.239 & 200.426 \\
\hline 2004 & 1.137 .034 & 569.136 & 416.260 & 151.638 \\
\hline 2005 & 1.201 .798 & 641.560 & 431.658 & 128.580 \\
\hline 2006 & 1.306 .063 & 735.932 & 452.343 & 117.788 \\
\hline \multicolumn{5}{|c|}{ M edicina de grupo } \\
\hline 2000 & 12.867 .635 & 3.430 .592 & 2.191 .429 & 7.245 .614 \\
\hline 2001 & 11.948 .769 & 4.054 .049 & 2.714 .604 & 5.180 .116 \\
\hline 2002 & 12.131 .479 & 5.080 .589 & 3.005 .267 & 4.045 .623 \\
\hline 2003 & 11.943 .671 & 6.287 .659 & 3.284 .036 & 2.371 .976 \\
\hline 2004 & 12.741 .168 & 7.626 .721 & 3.598 .043 & 1.516 .404 \\
\hline 2005 & 13.562 .282 & 8.698 .800 & 3.746 .121 & 1.117 .361 \\
\hline 2006 & 14.229 .013 & 9.442 .326 & 3.818 .079 & 968.608 \\
\hline \multicolumn{5}{|c|}{ Seguradora especializada em saúde } \\
\hline 2000 & 4.605 .576 & 1.464 .618 & 954.952 & 2.186 .006 \\
\hline 2001 & 4.590 .394 & 2.013 .851 & 964.292 & 1.612 .251 \\
\hline 2002 & 4.347 .310 & 2.427 .089 & 956.949 & 963.272 \\
\hline 2003 & 4.410 .816 & 3.121 .523 & 949.863 & 339.430 \\
\hline 2004 & 4.269 .373 & 3.281 .408 & 889.997 & 97.968 \\
\hline 2005 & 4.122 .174 & 3.281 .088 & 802.452 & 38.634 \\
\hline 2006 & 4.075 .850 & 3.334 .485 & 719.276 & 22.089 \\
\hline
\end{tabular}

Fontes: Sistema de Informações de Beneficiários - AN S/M S - 12/2006, RPS/AN S/M S - 12/2006 e Cadastro de O peradoras/ANS/ MS - 12/2006.

N ota: Até2004, o total podenão corresponder à soma das parcelas devido a inconsistências de informações sobrea modalidade da operadora. 


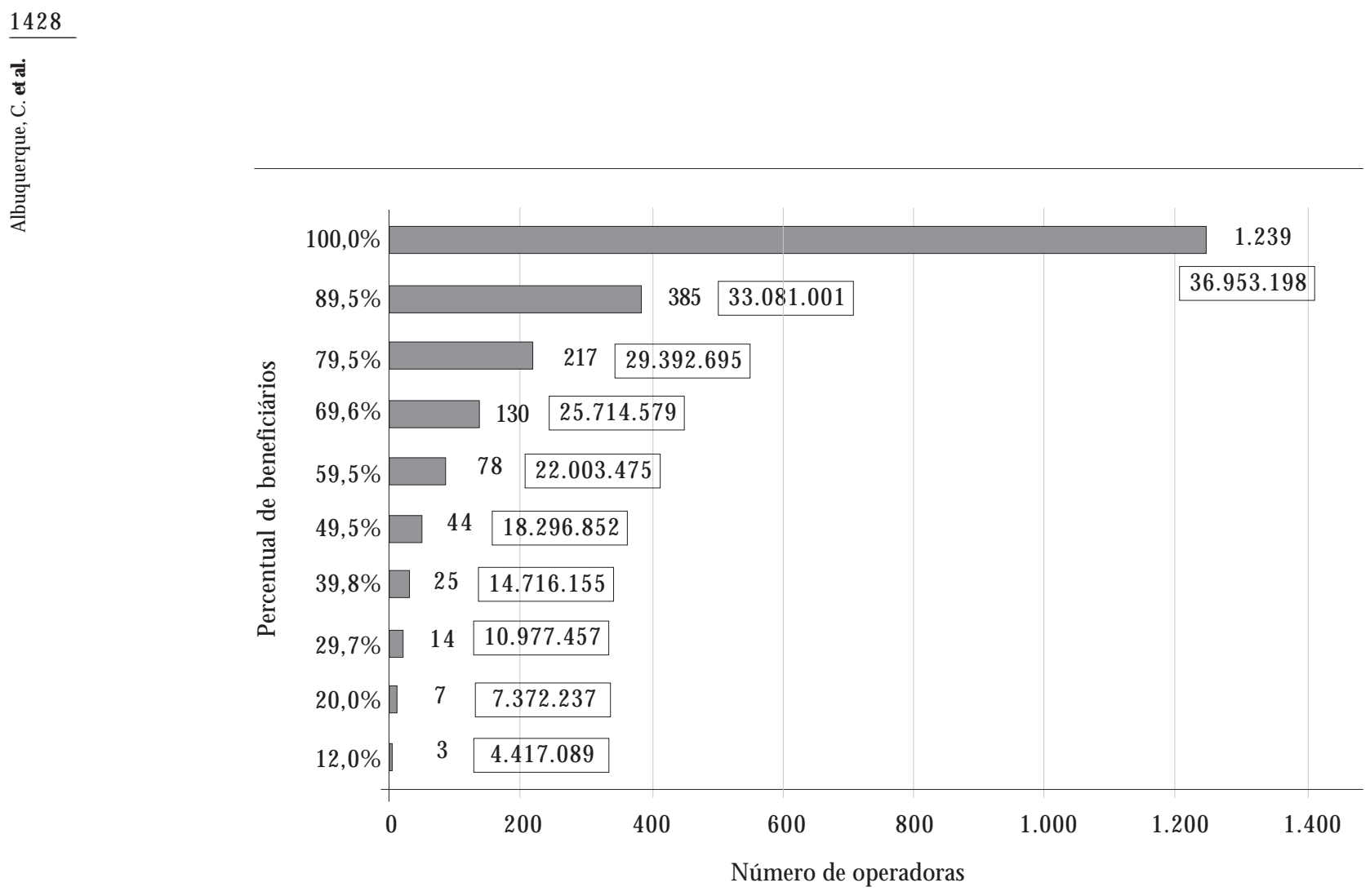

Figura 4. Curva $A B C$ da distribuição dos beneficiários de planos de assistência médica entre as operadoras. Brasil, dezembro de 2006.

Fontes: Sistema de Informações de Beneficiários - AN S/M S - 12/2006 e Cadastro de O peradoras/AN S/M S - 12/2006

Tabela 2. Beneficiários e operadoras segundo abrangência geográfica do plano de assistência médica.

\begin{tabular}{lrrc}
\hline \multirow{2}{*}{$\begin{array}{c}\text { Abrangência } \\
\text { geográfica }\end{array}$} & \multicolumn{2}{c}{ Beneficiários } & \multirow{2}{*}{ Operadoras } \\
\cline { 2 - 3 } & \multicolumn{1}{c}{ Qtde. } & $\%$ & \\
\hline Estadual & 3.537 .828 & 10 & 327 \\
Grupo de estados & 1.774 .949 & 5 & 123 \\
Grupo de municípios & 15.473 .116 & 42 & 836 \\
M unicipal & 1.950 .363 & 5 & 434 \\
Nacional & 11.076 .159 & 30 & 409 \\
Sem identificação & 3.140 .783 & 8 & 768 \\
Total & 36.953 .198 & 100 & não se aplica \\
\hline Fontes: Sistema deInformações deBeneficiários-ANS/M S- 12/ \\
2006, Cadastro deOperadoras/AN S/M S- 12/2006 eRPS/ANS/MS \\
- 18/05/2007.
\end{tabular}

Observando os sistemas de saúde dos países da Organização de Cooperação para o Desenvolvimento Econômico (OCDE) $)^{19}$, a média verificada nos países foi de 4,1 leitos por mil/habi- tantes, valor próximo ao encontrado em países como a Bélgica, Austrália, França, Suíça e Reino Unido. No ano de 2005, o Brasil dispunha de 2,4 leitos por mil habitantes (AM S/IBGE); deles, os leitos do SU S totalizavam 1,8 para cada mil habitantes e, para uma aproximação da realidade do setor suplementar, se calculada a oferta pelos leitos que não estão contratados pelo SUS e a população com planos de assistência médica, chega-se ao indicador de 2,9 leitos para cada mil beneficiários.

A distribuição da oferta da assistência hospitalar pelo SUS e pelo setor suplementar tem reflexo na produção de serviços de saúde do país. Segundo análise dos dados da PNAD/IBGE ${ }^{20}$, a maior parte de todas as internações realizadas no país no ano anterior à pesquisa foi paga pelo SUS, isto é, 70\% delas, aí incluídas as internações feitas pelo SUS em pacientes que possuem plano de saúde. 0 restante das internações foi financiado por meio do plano de saúde $(25 \%)$ e pelo gasto privado direto (5\%).

No ano de 2006, excetuadas as operadoras da modalidade autogestão patrocinada, desobri- 
gadas de enviar informações econômico-financeiras, a receita de contraprestações foi de aproximadamente $\mathrm{R} \$ 40$ bilhões e as despesas assistenciais de cerca de $R \$ 30$ bilhões, registrando-se uma sinistralidade média da ordem de $78 \%$ nas operadoras médico-hospitalares. Com base nestes dados, é possível estimar para as operadoras médico-hospitalares uma receita média mensal de $R \$ 81,70$ por beneficiário.

Em 2004, considerando as três esferas de governo, o gasto do SUS foi de R $\$ 65$ bilhões $^{21}$ e 0 gasto privado em saúde, de aproximadamente $\mathrm{R} \$ 72$ bilhões. Deste último, $\mathrm{R} \$ 32$ bilhões são provenientes da receita das operadoras de planos privados em 2004 e R $\$ 40$ bilhões referem-se ao gasto efetuado pelas famílias com assistência privada à saúde em $2003^{22}$, excluindo o gasto com planos de saúde das famílias que já está contabilizado na receita das operadoras, e incluindo o gasto com medicamentos, que é o maior gasto privado direto.

Este cál culo não contabiliza o gasto indireto do governo em saúde, proveniente das desonerações tributárias, estimadas pela Secretaria da Receita Federal do M inistério da Fazenda em aproximadamente $\mathrm{R} \$ 8$ bilhões, para 0 ano de $2007^{23}$. Parte desse recurso refere-se a deduções com planos privados, efetuadas no Imposto de Renda por pessoas físicas ejurídicas, o que deveria ser adicionado ao gasto público e subtraído do privado nos cálculos do gasto total em saúde. Também não são considerados os gastos com os hospitais universitários públicos e com a assistência à saúde para clientela fechada como, por exemplo, as forças armadas.

0 gasto do SU S em 2004 foi de $R$ \$359,30 por habitante e o do setor de planos privados foi de $\mathrm{R} \$ 980,40$ por beneficiário.

\section{Consideraçõesfinais}

O mercado de planos privados de saúde no Brasil éainda pouco conhecido epouco considerado no planejamento do Sistema de Saúde no país. Nos últimos anos, após a Lei no 9.656/98 ea criação da ANS, verifica-se uma melhoria na quantidade e qualidade de dados sobre esse mercado, assim como uma maior difusão de informações e análises sobre o tema, contribuindo para a integração do mercado de saúde suplementar na formulação de políticas e no planejamento em saúde.

Neste estudo, observou-se um crescimento do mercado de planos de assistência médica que acompanhou o da população brasileira. Grande parte dos beneficiários está na faixa etária de 20 a 49 anos e concentra-se nos municípios mais populosos e de maior industrialização do país, vinculados na sua maioria a planos coletivos, possivelmente devido à inserção no mercado detrabaIho. A manutenção da participação percentual de idosos na saúde suplementar não faz esperar um aumento na sinistralidade que se justifique pela alteração do perfil demográfico desta população.

A significativa expansão dos planos coletivos, em detrimento dos individuais, suscita a necessidade de estudos que avaliem em que medida este fenômeno mantém relação com o emprego formal e a renda, bem como as suas formas de contratação, se empresarial ou por adesão, ea possibilidade destes estarem relacionados à migração dos beneficiários de planos individuais.

0 mercado de planos privados é concentrado no que tange aos beneficiários. Embora existam mais de mil empresas que operam planos de saúde, a maioria dos beneficiários está concentrada em poucas operadoras. Este mercado caracteriza-se pela maior comercialização de planos com abrangência geográfica regional; contudo, apresenta um relevante mercado de abrangência nacional, com mais de onze milhões de beneficiários. A partir de 2001, houve maior número de cancelamentos de registros de operadoras, em relação aos novos registros solicitados, fenômeno possivelmente associado às novas regras.

Quanto à rede de prestadores, épossível identificar o imbricamento dos setores público e privado, ligado às operadoras, na prestação da assistência à saúde. Há sobreposição de prestadores públicos e contratados pelas operadoras, bem como sobreposição dos mesmos prestadores nas diversas operadoras. A questão da dupla porta de entrada, com o beneficiário de plano privado, sem determinada cobertura assistencial, tendo acesso facilitado aos serviços com a cobrança posterior ao SUS, é um tema que merece ser estudado.

0 gasto em saúde diferiu segundo a fonte de financiamento, observando-se no mercado de saúde suplementar um gasto por indivíduo mais de duas vezes superior àquele do SUS para a população brasileira.

Por fim, ressalta-seque, apesar do vínculo dos autores à Agência Nacional de Saúde Suplementar, os posicionamentos aqui apresentados não possuem caráter institucional. São algumas contribuições para a análise e 0 debate dos temas relacionados à assistência suplementar à saúde no país. 


\section{Colaboradores}

C Alburquerque, M F Piovesan, IS Santos, ACM M artins, AL Fonseca eD Sasson eKA Simõesparticiparam igualmente de todas as etapas da elaboração do artigo.

\section{Referências}

1. Lei $n 09.956$ de 03 de Junho de 1998. Dispõe sobre os planos e seguros privados de assistência à saúde. Diário Oficial da União 1998; 4 jun.

2. Instituto Brasileiro de Geografia e Estatística. Pesquisa Nacional por amostra de Domicílios: acesso e utilização de serviços de saúde. [acessado $2007 \mathrm{M}$ ai 09]. Disponível em: http://www.ibge.gov.br/ trabalho_e_rendimento/Pesquisa_Nacional_por_ Amostra_de_Domicílios_Anual/2003/PN AD saude/

3. Cordeiro H. As empresas médicas: as transformações capitalistas da prática médica. Rio de Janeiro: Graal; 1984

4. Oliveira JÁ de A, Teixeira SM F. (In)Previdência Social no Brasil - 60 anos de história da previdência no Brasil. Petrópolis: Vozes; 1986.

5. Noronha JC, Levcovitz E. AIS - SUDS - SUS: OS caminhos do direito à saúde. In: Reinaldo Guimarães, Ricardo Tavares, organizadores. Saúde e sociedade no Brasil: anos 80. Rio de Janeiro: RelumeDumará; 1994. p.73-111.

6. Faveret PF, Oliveira PJ. A universalização excludente: reflexões sobre as tendências do sistema de saúde. Dados 1990; 33(2):257-283.

7. Almeida CM. O mercado privado de serviços de saúde no Brasil: panorama atual e tendências da assistência médica suplementar. Rio de Janeiro: IPEA; 1998. [Texto para discussão no 599]

8. Almeida CM. Reforma do Estado e reforma de sistemas de saúde. Cien Saude Colet 1999; 4(2):263-286.

9. Bahia L. M edidas e padrões das relações público-privada: seguros e planos de saúde no Brasil [tese]. Rio de Janeiro (RJ): Escola de Saúde Pública, Fundação Oswaldo Cruz; 1999.

10. Bahia L. Planos privados de saúde: luzes e sombras no debate setorial dos anos 90. Cien Saude Colet 2001; 6(2):329-339.

11. Oliveira FB, Beltrão, Kaiso I, Ferreira MG. Reforma da Previdência. Brasília: IPEA; 1997.

12. Lima ALGS, Pinto MMS. Fontes para a história dos 50 anos do M inistério da Saúde. História, Ciências, Saúde - M anguinhos 2003;10(3):1037-1051.

13. Bahia L, Antunes LR, Cunha TCA, Martins WSN Planos de Saúde no Brasil: origens e trajetórias. 1a ed. Rio de Janeiro: Leps/M inistério da Saúde; 2005.

14. Lei 8.078 de 11 de setembro de 1990. Dispõe sobre a proteção do consumidor e dá outras providências. Diário Oficial da U nião 1990; 12 set.
15. Bahia L, Santos IS, Gama AM . A agenda de regulamentação dos planos e seguros de saúde: Notas sobre 0 debate no Legislativo e Executivo. In: Anais do VII Congresso Latinoamericano de M edicina Social e do XI Congresso de La Asociación Internacional de Políticas de Salud; 2000; Cuba, H avana.

16. Lei $n=9.961$ de 28 de Janeiro de 2000. Dispõe sobre a criação da Agência Nacional de Saúde Suplementar - ANS e dá outras providências. Diário Oficial da União 2000; 29 jan.

17. Agência Nacional de Saúde Suplementar. Caderno de Informação da Saúde Suplementar. Rio de Janeiro: ANS; 2007.

18. Bahia L, Luiz RR, Salm C, Costa AJL, Kale PL, Cavalcanti M LT. O mercado de planos e seguros de saúde no Brasil: uma abordagem exploratória sobre a estratificação das demandas segundo a PNAD 2003. Cien Saude Colet 2006; 11(4):951-965.

19. Organization for Economic Corporation Development. OECD Health Data, October 2006. [acessado 2007 M ai 09]. Disponível em: http://www.oecd.org/ document/16/0,3343,en_2649_37407_2085200_ 1_1_1_37407,00.htm

20. Porto $S M$, Santos IS, U gá MAD. A utilização de serviços de saúde por sistema de financiamento. Cien Saude Colet 2006; 11(4): 895-910.

21. IDB 2006. [acessado 2007 Dez 25]. Disponível em: http://www.datasus.gov.br/cgi/idb2006/matriz.htm

22. Instituto Brasileira de Geografia e Estatística. Pesquisa de Orçamentos Familiares 2003. Rio de Janeiro: IBGE; 2003.

23. Secretaria da Receita Federal. Coordenação-Geral de Política Tributária. Demonstrativo dos Gastos Governamentais Indiretos de Natureza Tributária (Gastos Tributários). Brasília; 2007. [acessado 2007 Mai 09]. Disponível em: http://www.receita. fazenda.gov.br/Arrecadacao/BenTributarios/ default.htm

Artigo apresentado em 20/06/2007

Aprovado em 21/08/2007

Versão final apresentada em 01/11/2007 